\title{
Reported Exposure and Emotional Reactivity to Daily Stressors: The Roles of Adult Age and Global Perceived Stress
}

\author{
Robert S. Stawski \\ Pennsylvania State University \\ David M. Almeida \\ Pennsylvania State University
}

\author{
Martin J. Sliwinski \\ Syracuse University \\ Joshua M. Smyth \\ Syracuse University
}

\begin{abstract}
A central goal of daily stress research is to identify resilience and vulnerability factors associated with exposure and reactivity to daily stressors. The present study examined how age differences and global perceptions of stress relate to exposure and emotional reactivity to daily stressors. Sixty-seven younger $\left(M_{\text {age }}=20\right)$ and 116 older $\left(M_{\text {age }}=80\right)$ adults completed a daily stress diary and measures of positive and negative affect on 6 days over a 14-day period. Participants also completed a measure of global perceived stress. Results revealed that reported exposure to daily stressors is reduced in old age but that emotional reactivity to daily stressors did not differ between younger and older adults. Global perceived stress was associated with greater reported exposure to daily stressors in older adults and greater stress-related increases in negative affect in younger adults. Furthermore, across days on which daily stressors were reported, intraindividual variability in the number and severity of stressors reported was associated with increased negative affect, but only among younger adults.
\end{abstract}

Keywords: aging, stress, emotion, emotional reactivity

The experience of both major life events and daily stressors has been linked to numerous negative physical health outcomes as well as mental health and psychological well-being (Baum \& Posluszny, 1999; Grzywacz, Almeida, Neupert \& Ettner, 2004; Kiecolt-Glaser, McGuire, Robles, \& Glaser, 2002; Pinquart \& Sörenson, 2003). In contrast to major life events, which are relatively rare, daily stressors (or "hassles") are minor stressors that occur with greater frequency and represent proximal aspects of stress in individuals' daily lives and environments. There has been increased interest in examining factors associated with exposure and reactivity to daily stressors in order to identify risk and protective factors (Almeida, 2005). Furthermore, it is important to understand who is at risk for experiencing daily stressors as well what factors exacerbate (or protect against) reactivity to these events because these minor hassles could have long-lasting, detrimental effects on physical and mental health (Lazarus, 1999; Zautra, 2003). The present study was conducted to examine reported exposure and emotional reactivity to daily stressors in younger (e.g., in their 20s) and older (e.g., in their 80s) adults and the role of

Robert S. Stawski and David M. Almedia, Department of Human Development and Family Studies and the Gerontology Center, Pennsylvania State University; Martin J. Sliwinski and Joshua M. Smyth, Department of Psychology and Center for Health and Behavior, Syracuse University.

This research was supported in part by National Institute on Aging Grant AG12448 and National Institute on Mental Health Grant 5T32MH018904.

Correspondence concerning this article should be addressed to Robert S. Stawski, Department of Human Development and Family Studies and the Gerontology Center, Pennsylvania State University, 118 Henderson Building, University Park, PA 16802 or Martin J. Sliwinski, Department of Psychology and Center for Health and Behavior, Syracuse University, Syracuse, NY 13244. E-mail: rss24@psu.edu or mjsliwin@syr.edu one's perceived stress in exposure and emotional reactivity to daily stressors.

Recent studies have shown that age plays an important role in daily stress processes (Mroczek \& Almeida, 2004; Sliwinski, Smyth, Hofer, \& Stawski, 2006), and understanding the role of age in exposure and reactivity to daily stressors is important because it can help characterize daily experiences and well-being across the life span. Furthermore, daily stress research can compliment theories of life-span emotional development such as Carstensen's socioemotional selectivity theory (SST; Carstensen, 1995; Carstensen, Isaacowitz, \& Charles, 1999). SST suggests that as the end of life approaches, preference is given to satisfying social and emotional goals as well as regulating one's emotions such that positive emotional experiences are maximized, and negative emotional experiences are minimized. Considerable evidence exists showing that reported exposure to daily stressors is associated with increases in negative affect (NA; Bolger, DeLongis, Kessler, \& Schilling, 1989; Bolger \& Schilling, 1991; Marco \& Suls, 1993; Smyth et al., 1998; van Eck, Nicolson, \& Berkhof, 1998; Zautra, Affleck, Tennen, Reich, \& Davis, 2005) and daily distress (Almeida \& Kessler, 1998; Bolger \& Zuckerman, 1995; Grzywacz et al., 2004; Serido, Almeida, \& Wethington, 2004). Because our emotions are inextricably linked to our experiences, daily stress research can help to understand the contexts associated with daily emotional experiences as well as the role daily stressors play in emotional experiences across the adult life span.

\section{Age Differences in Daily Stressor Exposure}

Previous research has shown that throughout midlife and into old age, the self-reported exposure to daily stressors decreases with 
age, which is consistent with SST. Almeida and Horn (2004) found that younger (25-39 years old) and middle-aged ( $40-59$ years old) adults reported experiencing daily stressors more frequently than did older adults (60-74 years old). Zautra, Finch, Reich, and Guarnaccia (1991) reported that in a sample of older adults ranging in age from 60 to $80(M=70)$, age was negatively associated with monthly reports of small life events. We are unaware of any research, however, showing that this pattern of results applies when examining very old adults. On the basis of previous research and theory (e.g., Almeida \& Horn, 2004; Carstensen, Fung, \& Charles, 2003), the perception of limited time should motivate older adults to minimize their exposure to situations potentially leading to the experience of negative emotions. As such, one would expect that the frequency of exposure to daily stressors in the very old would be substantially less than in young adults. Thus, the first goal of the present study was to compare the frequency of reported exposure to daily stressors for young and very old adults.

\section{Age Differences in Emotional Reactivity to Daily Stressors}

Given that daily stressors elicit negative emotions, the extent to which daily stressors increase one's level of negative emotions can inform researchers about emotional reactivity to daily stressors. Using daily diary data from a nationally representative sample of 25- to 74-year-olds, Mroczek and Almeida (2004) found that older adults exhibited the greatest increase in NA associated with the experience of daily stressors. In contrast, using a momentary sampling methodology, Uchino, Berg, Smith, Pearce, and Skinner (2006) found the exact opposite effect with a sample of 36- to 75-year-olds. Uchino et al. (2006) found that stress-related increases in NA decreased with advancing age. Thus, with respect to daily stressor effects on NA, the evidence is inconsistent.

Mroczek and Almeida's (2004) results demonstrated age differences in the effect of daily stressors on NA; however, it remains unclear whether a similar pattern of results would be observed, during very old age, or for positive affect (PA). It is important to consider the effects of daily stressors on PA in advanced age because PA has been argued to reflect energy, enthusiasm, and alertness, whereas NA reflects distress and uneasiness (Watson, 1988; Watson, Clark, \& Tellegen, 1988). Furthermore, PA is thought to be important for maintaining and increasing cognitive, physical, and social function as well as overall emotional wellbeing (Frederickson, 2001; Frederickson \& Joiner, 2002). A number of studies have examined the association between daily events or stressors and PA; however, only one of these studies has explicitly examined age differences in stress-related changes in PA (see Uchino et al., 2006). Although decreases in self-reported PA associated with the experience of daily stressors have been found in a majority of studies (Smyth et al., 1998; van Eck et al., 1998; Zautra et al., 2005), Uchino et al. (2006) found that daily stressors were associated with increased PA and that adult age, across midlife, did not moderate this association. Thus, a second goal of the present study was to extend previous research by examining age differences in young and very old adults' negative and positive emotional responses to daily stressors.

Taken together, there is evidence that age plays an important role in both exposure and reactivity to daily stressors, with older adults reporting experiencing fewer daily stressors than their younger coun- terparts but perhaps being more emotionally reactive to the stressors that they do experience. Age, however, is not the only variable that has been shown to be an important predictor of exposure and reactivity to daily stressors. Previous research has also demonstrated that personality and contextual factors play important roles in predicting reported exposure and reactivity to daily stressors. Studies have shown that individuals reporting higher levels of neuroticism experience daily stressors more frequently and are more emotionally reactive compared with less neurotic individuals (Bolger \& Schilling, 1991; Bolger \& Zuckerman, 1995). Furthermore, one study has shown that the effect of neuroticism on emotional reactivity to stress increases with advancing age (Mroczek \& Almeida, 2004). Similarly, van Eck and colleagues (van Eck et al., 1998) demonstrated that a contextual factor, global perceived stress (GPS), as measured using Cohen, Kamarck, and Marmelstein's (1983) Perceived Stress Scale, was associated with greater exposure and emotional reactivity to daily stressors. van Eck et al. (1998) argued that GPS represents the extent to which an individual appraises their current life demands to be uncontrollable or overwhelming. Examining the association among appraisals of current life demands and exposure and reactivity to daily stressors can complement research examining the role of personality factors such as neuroticism. Whereas personality factors elucidate the role of traits and dispositions in reported exposure and reactivity to daily stressors, appraisals of current life demands can inform researchers about how an individual's current environmental demands (contextual factors) are associated with daily stress processes.

To our knowledge, no studies have examined adult age differences in the effects of GPS on reported exposure and reactivity to daily stressors. It is important to consider age differences in the role of GPS on exposure and reactivity to daily stressors because high levels of environmental demands may place older adults at a greater likelihood for experiencing daily stressors and/or being more emotionally reactive to these experiences. Thus, a third goal of the present study was to examine age differences in the role of GPS on reported exposure and emotional reactivity to daily stressors.

\section{Characterizing the Stress Day in Daily Stress Research}

In daily stress research, the day (i.e., stress day vs. nonstress day) is often the unit of analysis of primary interest. However, not all stress days are necessarily equal. A stress day may consist of a single stressor or multiple stressors. Similarly, the severity of stressors experienced may be very different from one day to the next. Thus, it is important to consider characteristics of the stress day, such as number of stressors experienced and severity of the stressors, as well as how intraindividual variability in the characteristics of the stress day relate to daily emotions. Such an examination would indicate whether emotional reactivity to daily stressors is driven by the simple occurrence of a stressor or whether having more stressors than usual, or more severe stressors than usual, might compound or exacerbate emotional reactions.

It is possible that the characteristics of stressful days may differ between younger and older adults, as well as by different levels of GPS. For instance, the average number of stressors and severity of stressors reported may be fewer for older adults compared with younger adults. Similarly, stress days for individuals reporting higher levels of GPS may be composed of greater numbers of stressors and more severe stressors. Thus, a fourth goal was to examine age and GPS as they relate to the number and severity of 
stressors reported across days when at least one stressor was reported. Furthermore, we sought to examine how intraindividual variability in the characteristics of stress days was associated with emotional reactions.

To reiterate, this study was conducted to accomplish four goals. First, we sought to examine age differences in self-reported daily stressor exposure and characteristics of the stress day. Second, we wanted to examine whether individual differences in GPS were associated with daily stressor exposure and characteristics of the stress day, as well as age differences in the effects of GPS. Third, we wanted to examine age and GPS differences in emotional reactivity to daily stressors, assessing the effects of daily stressors on both NA and PA. Finally, we wanted to examine the extent to which intraindividual variability in characteristics of stressor days (i.e., number and severity) potentially exacerbate emotional reactions to daily stressors as well as age and GPS as potential moderators of such effects. Data for the present study were collected from samples of older $\left(M_{\text {age }}=80\right)$ and younger adults $\left(M_{\text {age }}=20\right)$, who completed measures of PA and NA (Lawton, Kleban, Dean, Rajagopal, \& Parmelee, 1992), and from a daily stressor inventory (Almeida, Wethington, \& Kessler, 2002), six times over a 14-day period.

\section{Method}

\section{Participants}

The younger adult sample consisted of 68 Syracuse University undergraduate students recruited from undergraduate psychology courses and via advertisements posted in student centers. One hundred sixteen older adults were recruited for this study. Sixtyfour of these participants were recruited from the greater Syracuse area by advertising in local newspapers and senior centers. Fiftytwo of the participants were residents of a senior residence community and volunteered for participation. The average ages for the younger and older adults were $20.48(S D=1.24)$ and $80.30(S D=$ $6.43)$, respectively. Younger adults reported completing 15.14 $(S D=1.42)$ years of education on average, whereas older adults reported completing $14.96(S D=2.40)$ years. Both groups had comparable proportions of men and women, with $28 \%$ of the older adult sample and $23 \%$ of the younger adult sample being men.

\section{Materials}

Daily stressors were assessed using the Daily Inventory of Stressful Events (DISE; Almeida et al., 2002). The DISE is a semistructured interview in which participants report whether any of a series of events had occurred within the past $24 \mathrm{hr}$. The version of the DISE included in this study consisted of five questions: (1) Did you have an argument or disagreement with anyone? (b) Did anything else happen that you could have argued or disagreed about, but you decided to let it pass? (c) Did anything happen to a close friend or relative that turned out to be stressful for you? (d) Did anything stressful happen regarding your personal health? (e) Did anything else happen that most people would consider stressful? Daily stress was defined three ways. First, a dichotomous variable was used to characterize days as either stress days (at least one stressor was reported) or nonstress days (no stressor reported). Given that at least one stressor was reported, we also characterized stress days on the basis of the number of stressors reported (maximum possible $=5$ ) and how severe, on average, the stressors experienced were reported to be $(1=$ not at all, $2=$ a little, $3=$ somewhat, $4=$ very).

PA and NA were assessed using a version of Lawton and colleagues' (Lawton et al., 1992) Philadelphia Geriatric Center Positive and Negative Affect Scales. The Positive and Negative Affect scales comprised five items each. The Positive Affect scale items were happy, interested, energetic, content, and warmhearted. The Negative Affect scale items were sad, annoyed, worried, irritated, and depressed. Participants indicated the extent to which they were experiencing each of the adjectives on a 5 -point likert scale $(1=$ not at all, $2=$ a little, $3=$ moderately, $4=$ quite a bit, $5=$ extremely), right now, at this very moment. Scores for PA and NA were obtained by summing the individuals' responses on all five items from each scale, respectively, with higher scores reflecting greater affective experience. Alphas ranged from .69 to .85 , for both scales, across the study days.

GPS was measured using Cohen et al.'s (1983) Perceived Stress Scale (PSS). The PSS consists of 14 items asking how often the individual had felt over the past month (e.g., "In the past month, how often have you felt nervous or "stressed" "In the past month, how often have you felt that you were on top of things?") and is considered a valid measure of general appraisals of how demanding or overburdened one's life is. Items were rated on a 5-point likert scale $(1=$ never, $2=$ almost never, $3=$ sometimes, $4=$ fairly often, 5 = very often), with positive items being reverse coded and a total score obtained by summing all 14 items. Higher scores reflect greater GPS during the time testing occurred. Cronbach's alpha was .85 for the full sample and .82 and .81 for younger and older adults, respectively.

\section{Procedure}

After being given an introduction to the study, participants provided informed consent and were tested on six occasions during an 8- to 14-day period. Half of the session took place in the morning (before 11:00 a. m.), and half took place in the afternoon (after 1:00 p. m.). Participants were tested individually and by the same research assistant on each of the sessions. PA and NA were measured at the beginning of each session, whereas daily stressors were assessed at the end of the session. Participants completed the PSS on their own, at home, between the second and third sessions.

\section{Analytic Strategy}

We used multilevel linear models (Snidjers \& Bosker, 1999) to examine the effects of daily stressors on daily affect. This methodology allows us to examine associations between stressors and affect at both the within- and between-person levels (Levels 1 and 2 , respectively). The following model was used to model the effects of age, daily stressors, and GPS on affect:

$$
\begin{gathered}
\operatorname{AFFECT}_{i j}=b_{0 j}+b_{1 j}\left(\overline{\operatorname{stress}_{i j}}\right)+e_{i j} \\
b_{0 j}=\beta_{00}+\beta_{01}(\text { age group })+\beta_{02}\left(\overline{\text { Stress }_{j}}\right) \\
+\beta_{03}(\mathrm{GPS})+\mathrm{u}_{0 j} \\
\mathrm{~b}_{1 j}=\beta_{10}+\beta_{11}(\text { age group })+\beta_{12}(\mathrm{GPS}),
\end{gathered}
$$


where $b_{0 j}$ is either the negative or PA score for session $i$ and person $j$. The parameter $b_{1 j}$ reflects the within-person daily stress effect. Because daily stressors were coded dichotomously $(0=$ no stress reported, $1=$ any stress reported), $b_{1 j}$ indicates the difference in affect on stress days compared with nonstress days. $\beta_{00}$ and $\beta_{10}$ are the average within-person intercept and daily stress effects (i.e., fixed effects), and $\mathrm{u}_{0 j}$ is the person-specific deviations from the intercept (i.e., random effect). $\beta_{01}$ and $\beta_{11}$ are Level 2 effects and reflect age differences in the average levels of affect and within-person daily stressor effects, respectively. $\beta_{03}$ and $\beta_{12}$ are Level 2 effects and represent GPS effects on daily affect and the within-person daily stressor effects, respectively, whereas $\beta_{02}$ reflects the between-person daily stressor effect. Equation 1 was also used as a basis for testing more complex models, including higher order interactions.

\section{Results}

The Results section is presented in three parts. First, we present descriptive statistics and correlations for the stress and affect variables. Second, we present models examining age and GPS associations with daily stressor exposure and the characteristics of stress days (i.e., number and severity of reported stressors). Third, we present a series of models examining the effects of age, GPS, and daily stressors, as well as within-person associations among characteristics of stress days, on daily negative and PA.

\section{Descriptive Statistics}

Table 1 displays descriptive statistics and correlations among the daily stress, GPS, and daily affect measures for the younger and older adults, respectively. Although there is evidence of a modest degree of association among the stress measures between persons for the older adults, $r(114)=.31, p<.01$, these variables were not correlated among the younger adults, $r(66)=.07$, $n s$. Furthermore, associations between the stress and affect variables were modest for both age groups (absolute values of the correlations range from .26 to .36), indicating that although stress and affect reports are related, these measures do not exhibit a high degree of colinearity.

\section{Age, GPS, and Exposure to Daily Stressors}

To test for age differences in reported exposure to daily stressors, we estimated a multilevel logistic model (SAS PROC NLMIXED), predicting self-reported daily stressor experience as a function of age group. The proportion of days on which at least one stressor was reported was $.77(S E=.03)$ for younger adults and $.44(S E=.04)$ for older adults (see Table 2 for stressor frequency by age and stressor type). This difference corresponded to an odds ratio of 4.17 (95\% confidence interval [CI]: 2.12, 6.21), indicating that the odds of reporting a stressor on a given day was over four times greater for younger adults. Next, we added GPS and the Age $\times$ GPS interaction to the model. We found that higher levels of perceived stress were associated with increased odds of experiencing daily stressors in older (odds ratio: $1.09,95 \%$ CI: 1.03 , 1.14 ) but not younger adults (odds ratio: $1.01,95 \%$ CI: $0.96,1.07$ ), a difference that approached significance $(p=.055)$. Adding perceived stress to the model reduced the odds ratio for the effect of age to 3.05 (95\% CI: $1.36,4.73$ ).

Given that not all stress days are necessarily the same, we wanted to examine age and GPS effects on the number of stressors reported across stress days as well as how severe the stressors experienced were reported to be. Using multilevel linear models, we estimated two models. First, we first examined age differences in the number of stressors and the self-reported severity of the stressors across stress days. Next, we added GPS to examine potential associations with stress-day characteristics as well as any age differences in associations between GPS and stress-day characteristics. The results of these models can be seen in Table 3 .

Across stress days, younger adults reported significantly greater numbers of stressors than did older adults (estimate $=.14, S E=$ $.07, p=.05)$, but the two groups did not differ in the self-reported severity of the stressors reported (estimate $=.13, S E=.14 . n s$ ). Adding GPS to the models revealed that higher levels of GPS were associated with greater numbers of reported stressors on stress days for both younger (estimate $=.02, S E=.009, p=.05$ ) and older adults (estimate $=.01, S E=.007, p=.05$ ). Furthermore, controlling for GPS reduced the age difference in number of stressors reported on stress days to a nonsignificant level (estimate $=.04, S E=.08, n s)$. GPS was not significantly related to

Table 1

Descriptive Statistics and Correlations Among Daily Stress, Global Perceived Stress, and Daily Affect for Younger and Older Adults

\begin{tabular}{|c|c|c|c|c|c|c|}
\hline Variable & $M$ & $S D$ & 1 & 2 & 3 & 4 \\
\hline \multicolumn{7}{|c|}{ Younger adults $(n=68)$} \\
\hline 1. Any stressor (no $=0$, yes $=1)^{\mathrm{a}}$ & 0.74 & 0.23 & - & & & \\
\hline 2. Perceived Stress Scale & 24.63 & 6.13 & .07 & - & & \\
\hline 3. Negative affect ${ }^{\mathrm{a}}$ & 6.76 & 1.60 & .08 & $.27^{*}$ & - & \\
\hline 4. Positive affect ${ }^{\mathrm{a}}$ & 14.51 & 2.90 & .11 & $-.33^{* *}$ & $-.28^{*}$ & - \\
\hline
\end{tabular}

Older adults $(n=116)$

1. Any stressor (no $=0$, yes $=1)^{\mathrm{a}}$

2. Perceived Stress Scale

3. Negative affect ${ }^{\mathrm{a}}$

4. Positive affect $^{\mathrm{a}}$

$\begin{array}{rlr}0.46 & 0.33 & - \\ 17.26 & 6.68 & .31^{\text {*** }} \\ 5.96 & 1.24 & .33^{* *} \\ 18.15 & 3.03 & -.12\end{array}$

18.15
1.24
3.03

${ }^{a}$ Mean value reflects average taken across study days.

${ }^{*} p<.05 . \quad{ }^{* * *} p<.01$. 
Table 2

Frequency of Stressors by Age and Stressor Type

\begin{tabular}{lccc}
\hline \multicolumn{1}{c}{ Stressor } & Younger & Older & $p$ \\
\hline $\begin{array}{l}\text { Did you have an argument or } \\
\text { disagreement with anyone? }\end{array}$ & $26 \%$ & $6 \%$ & $<.01$ \\
$\begin{array}{l}\text { Did anything else happen that you } \\
\quad \text { could have argued or disagreed } \\
\text { about, but you decided to let it }\end{array}$ & $34 \%$ & $13 \%$ & $<.01$ \\
$\quad$ pass? & & & \\
$\begin{array}{l}\text { Did anything happen to a close } \\
\quad \text { friend or relative that turned out }\end{array}$ & $13 \%$ & $17 \%$ & .22 \\
$\quad$ to be stressful for you? & & & \\
$\begin{array}{l}\text { Did anything stressful happen } \\
\quad \text { regarding your personal health? }\end{array}$ & $11 \%$ & $8 \%$ & .35 \\
$\begin{array}{l}\text { Did anything else happen that most } \\
\text { people would consider stressful? }\end{array}$ & $37 \%$ & $22 \%$ & $<.01$ \\
\hline
\end{tabular}

stressor severity ratings for either age group, and there were no age differences in the effects of GPS on either the number of stressors or severity of stressors reported.

\section{Age, GPS, and Emotional Reactivity to Daily Stressors}

To test whether individuals exhibited emotional reactivity to the stressors they reported experiencing, we estimated a series of linear multilevel models to examine the effects of age, daily stressors, and GPS on daily negative and PA. For these initial models, the daily stress effect was estimated using the dichotomous daily stress variable. Such models indicate the extent to which one's affect changed as a function of whether they reported experiencing any stressors. The results of these models for NA can be seen in Table 4. The first model (NA Model 1) simply examined whether there were age differences in daily NA. Older adults reported significantly less daily NA on average than did younger adults (estimate $=.80, S E=.22, p<.01$ ).

Next, between- and within-person daily stress, GPS effects, as well as their interactions with age were entered as predictors of daily NA (see Table 3, NA Model 2). The within-person daily stressor effect was significant for both younger (estimate $=.77, S E$ $=.27, p<.01$ ) and older adults (estimate $=.75, S E=.16, p<$ .01 ), indicating that NA was higher on stress days compared with nonstress days. The difference between age groups, however, was not statistically significantly (estimate $=.02, S E=.02, n s$ ), indicating that the change in NA was comparable between age groups. Additionally, individuals scoring high on the measure of GPS reported higher levels of NA. This was true for both younger (estimate $=.07, S E=.03, p<.05$ ) and older (estimate $=.04, S E$ $=.01, p<.01)$ adults, and there was no age difference in this effect. Thus, daily stressors and global perceptions of stress each uniquely predict daily NA. Furthermore, it is worth noting that the age difference in NA was reduced to a nonsignificant level after controlling for the effects of daily stressors (estimate $=.33, S E=$ $.65, n s)$.

Next, we tested whether GPS moderated the effect of daily stressors on NA and whether this association differed between younger and older adults. Table 3 (NA Model 3) shows the results from the model, adding the interaction between GPS and daily stressors for younger and older adults as well as the three-way interaction with age. The GPS $\times$ Within-Person Daily Stressor

Table 3

Parameter Estimate for the Effects of Age and Global Perceived Stress on the Number of Stressors and Severity of Stressors Reported Across Stress Days

\begin{tabular}{|c|c|c|c|c|c|c|c|c|}
\hline \multirow[b]{3}{*}{ Variable } & \multicolumn{4}{|c|}{ Number of stressors } & \multicolumn{4}{|c|}{ Severity of stressors } \\
\hline & \multicolumn{2}{|c|}{ Model 1} & \multicolumn{2}{|c|}{ Model 2} & \multicolumn{2}{|c|}{ Model 1} & \multicolumn{2}{|c|}{ Model 2} \\
\hline & Estimate & $S E$ & Estimate & $S E$ & Estimate & $S E$ & Estimate & $S E$ \\
\hline \multicolumn{9}{|c|}{ Fixed effects } \\
\hline \multicolumn{9}{|l|}{ Intercept } \\
\hline Younger & 1.53 & $.06^{* *}$ & 1.45 & $.07^{* *}$ & 1.31 & $.11^{* * *}$ & 1.40 & $.15^{* *}$ \\
\hline Older & 1.39 & $.05^{* *}$ & 1.41 & $.05^{* *}$ & 1.19 & $.08^{* * *}$ & 1.20 & $.08^{* *}$ \\
\hline Difference & 0.14 & $.07^{*}$ & 0.04 & .08 & 0.13 & .14 & 0.20 & .17 \\
\hline \multicolumn{9}{|c|}{ Global Perceived Stress } \\
\hline Younger & & & 0.02 & $.009^{*}$ & & & -0.02 & .02 \\
\hline Older & & & 0.01 & $.007^{*}$ & & & 0.01 & .01 \\
\hline Difference & & & 0.01 & .01 & & & -0.03 & .02 \\
\hline
\end{tabular}

Variance component

\begin{tabular}{|c|c|c|c|c|c|c|c|c|}
\hline \multicolumn{9}{|c|}{ Between person } \\
\hline \multicolumn{9}{|l|}{ Intercept } \\
\hline Younger & 0.07 & $.03^{*}$ & 0.06 & $.03^{*}$ & 0.44 & $.20^{*}$ & 0.44 & $.19^{*}$ \\
\hline Older & 0.09 & $.03^{* * *}$ & 0.08 & $.03^{* *}$ & 0.11 & .12 & 0.10 & .12 \\
\hline \multicolumn{9}{|l|}{ Within person } \\
\hline \multicolumn{9}{|l|}{ Residual } \\
\hline Younger & 0.59 & $.05^{* *}$ & 0.59 & $.05^{* *}$ & 1.86 & $.18^{* * *}$ & 1.88 & $.19^{* *}$ \\
\hline Older & 0.36 & $.03^{* *}$ & 0.35 & $.03^{* *}$ & 1.49 & $.15^{\text {*** }}$ & 1.50 & $.15^{* *}$ \\
\hline
\end{tabular}

${ }^{*} p<.05 .{ }^{* *} p<.01$. 
Table 4

Multilevel Model Parameter Estimates for the Effects of Age, Daily Stressor, and Global Perceived Stress on Daily Negative Affect

\begin{tabular}{|c|c|c|c|c|c|c|}
\hline \multirow[b]{2}{*}{ Variable } & \multicolumn{2}{|c|}{ NA Model 1} & \multicolumn{2}{|c|}{ NA Model 2} & \multicolumn{2}{|c|}{ NA Model 3} \\
\hline & Estimate & $S E$ & Estimate & $S E$ & Estimate & $S E$ \\
\hline \multicolumn{7}{|c|}{ Fixed effects } \\
\hline \multicolumn{7}{|l|}{ Intercept } \\
\hline Younger & 6.76 & $.19^{* *}$ & 6.04 & $.63^{* *}$ & 6.29 & $.64^{* * *}$ \\
\hline Older & 5.96 & $.11^{* * *}$ & 5.71 & $.15^{* *}$ & 5.70 & $.15^{\text {** }}$ \\
\hline Difference & 0.80 & $.22^{* *}$ & 0.33 & .65 & 0.59 & .66 \\
\hline \multicolumn{7}{|c|}{ Daily Stressor (WP) } \\
\hline Younger & & & 0.77 & $.27^{* * *}$ & 0.19 & .34 \\
\hline Older & & & 0.75 & $.16^{* *}$ & 0.85 & $.17^{* * *}$ \\
\hline Difference & & & 0.02 & .32 & -0.65 & $.38^{\dagger}$ \\
\hline \multicolumn{7}{|c|}{ Daily Stressor (BP) } \\
\hline Younger & & & 0.40 & .82 & 0.22 & .83 \\
\hline Older & & & 0.82 & $.31^{* *}$ & 0.80 & $.31^{* * *}$ \\
\hline Difference & & & -0.42 & .87 & -0.59 & .88 \\
\hline \multicolumn{7}{|c|}{ Global Perceived Stress } \\
\hline Younger & & & 0.07 & $.03^{*}$ & -0.02 & .04 \\
\hline Older & & & 0.04 & $.01^{* *}$ & 0.04 & $.01^{* *}$ \\
\hline Difference & & & 0.03 & .03 & -0.06 & .04 \\
\hline \multicolumn{7}{|c|}{$\begin{array}{l}\text { Global Perceived Stress } \\
\times \text { Daily Stressor } \\
\text { (WP) }\end{array}$} \\
\hline Younger & & & & & 0.12 & .04 \\
\hline Older & & & & & 0.04 & $.02^{\dagger}$ \\
\hline Difference & & & & & 0.08 & $.04^{\dagger}$ \\
\hline
\end{tabular}

Variance component

$\begin{array}{lllllll}\text { BP } & & & & & & \\ \quad \text { Intercept } & & & & & & \\ \quad \text { Younger } & 1.77 & .43^{* *} & 1.59 & .40^{* *} & 1.64 & .41^{* *} \\ \quad \text { Older } & 1.15 & .20^{* *} & 0.17 & .10^{*} & 0.17 & .10^{*} \\ \text { WP } & & & & & & \\ \quad \text { Younger } & 4.30 & .33^{* *} & 4.24 & .33^{* *} & 4.13 & .32^{* *} \\ \quad \text { Older } & 2.28 & .13^{* *} & 2.07 & .13^{* *} & 2.07 & .13^{* *}\end{array}$

Note. $\mathrm{NA}=$ negative affect; $\mathrm{WP}=$ within person; $\mathrm{BP}=$ between person. ${ }^{\dagger} p<.07 .{ }^{*} p<.05 .{ }^{* * *} p<.01$.

interaction was significant for younger adults (estimate $=.12, S E$ $=.04, p<.01$ ) but only moderately significant for older adults (estimate $=.04, S E=.02, p=.06$ ), and the age difference for this effect approached significance (estimate $=.08, S E=.04, p=$ .06). Figure 1 displays the interaction and indicates that daily stress-related increases in NA are greatest among individuals reporting the highest levels of GPS, especially among the younger adults.

A similar series of models was estimated to examine the effects of age, daily stressors, and GPS on PA. The results of these models can be seen in Table 5. The first model (PA Model 1) simply examined whether there were age differences in daily PA and revealed that older adults report higher average levels of daily PA than younger adults (estimate $=-3.63, S E=.45, p<.01$ ). Next, between- and within-person daily stressors and GPS effects were added to the model. The results of this model can be seen in Table 3 (PA Model 2). The within-person daily stressor effect was significant for older adults (estimate $=-0.49, S E=.20, p<.05$ ) but not for younger adults (estimate $=-0.21, S E=.41, n s$ ), indicating that PA was reliably lower on stress days compared with nonstress days, but only for older adults. The age difference in the within-person daily stressor effect, however, was not significant (estimate $=.29, S E=.45, n s)$. Finally, we tested whether GPS moderated daily stressor-related changes in PA and whether this differed as a function of age group. The GPS $\times$ Daily Stressor interaction was not significant for either age group, nor did this interaction differ between age groups (all $p \mathrm{~s}>.25$ ).

These first sets of analyses examining emotional reactivity to daily stressors showed that both younger and older adults' NA increases on stressful days compared with nonstressful days and that older adults' PA decreases on stressful days. However, given that there was significant intraindividual variability in the number and severity of stressors reported across stress days, we examined the extent to which intraindividual variability in these characteristics of stress days was associated with emotional reactions. To do this, we estimated multilevel models in which the analyses were constrained to only days on when at least one stressor was reported. We constructed within-person estimates of the effects of number of stressors reported and severity of stressors reported by obtaining deviations of each individual from their own average number of stressors or severity of stressors \#Stressors $_{\mathrm{ij}}$ \#Stressors ${ }_{j}$ ). The same methods were used for the stressor severity estimates.

Table 6 shows the estimates of how day-to-day fluctuations in the number and severity of stressors, across stress days, are related to daily negative and PA. On days when younger adults report greater numbers of stressors than usual, they also report greater levels of NA (estimate $=.43, S E=.19, p<.05$ ), whereas experiencing more stressors than usual had no effect on older adults' NA (estimate $=.04, S E=.20, n s$ ). Similarly, across stress days, when younger adults rated their stressors as more severe than usual, they also reported higher levels of NA (estimate $=.23$, $S E=.11, p<.05)$, whereas older adults did not (estimate $=$ $-0.05, S E=.10, n s)$, and the difference in these two effects was marginally significant (estimate $=.28, S E=.15, p=.06$ ).

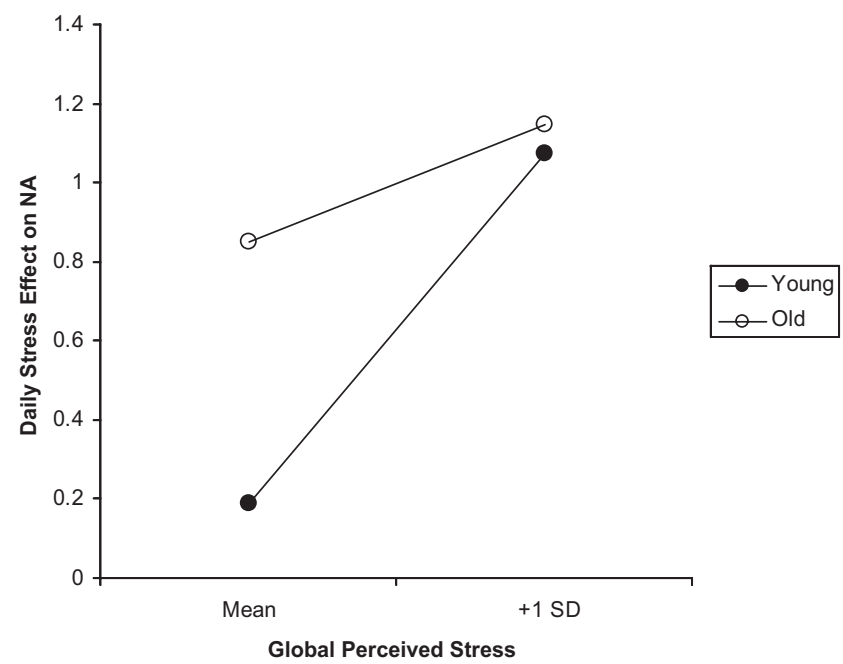

Figure 1. The effects of daily stressors on daily negative affect (NA) for average and high- (+1 standard deviation) global perceived stress individuals as a function of age group. 
Table 5

Multilevel Model Parameter Estimates for the Effects of Age, Daily Stressor, and Global Perceived Stress on Daily Positive Affect

\begin{tabular}{|c|c|c|c|c|}
\hline \multirow[b]{2}{*}{ Variable } & \multicolumn{2}{|c|}{ PA Model 1} & \multicolumn{2}{|c|}{ PA Model 2} \\
\hline & Estimate & $S E$ & Estimate & $S E$ \\
\hline \multicolumn{5}{|c|}{ Fixed effects } \\
\hline \multicolumn{5}{|l|}{ Intercept } \\
\hline Younger & 14.52 & $.35^{* *}$ & 14.06 & $1.12^{* *}$ \\
\hline Older & 18.15 & $.28^{* * *}$ & 17.88 & $0.51^{* *}$ \\
\hline Difference & -3.63 & $.45^{* * *}$ & -3.82 & $1.23^{* *}$ \\
\hline \multicolumn{5}{|c|}{ Daily stressor (WP) } \\
\hline Younger & & & -0.21 & 0.41 \\
\hline Older & & & -0.49 & $0.20^{*}$ \\
\hline Difference & & & 0.29 & 0.46 \\
\hline \multicolumn{5}{|c|}{ Daily stressor (BP) } \\
\hline Younger & & & 1.63 & 1.44 \\
\hline Older & & & -0.08 & 0.85 \\
\hline Difference & & & 1.71 & 1.67 \\
\hline \multicolumn{5}{|c|}{ Global Perceived Stress } \\
\hline Younger & & & -0.16 & $0.05^{* *}$ \\
\hline Older & & & -0.12 & $0.04^{* *}$ \\
\hline Difference & & & -0.04 & 0.07 \\
\hline
\end{tabular}

Variance component

\begin{tabular}{lllll}
$\begin{array}{l}\text { Between person } \\
\text { Intercept } \\
\quad \text { Younger }\end{array}$ & & & & \\
$\quad$ Older & 6.65 & $1.42^{* * *}$ & 5.67 & $1.27^{* *}$ \\
Within person & 8.42 & $1.19^{* *}$ & 7.53 & $1.08^{* *}$ \\
$\quad$ Younger & & & & \\
Older & 9.41 & $0.73^{* * *}$ & 9.45 & $0.73^{* *}$ \\
\hline
\end{tabular}

Note. $\mathrm{PA}=$ positive affect; $\mathrm{WP}=$ within person; $\mathrm{BP}=$ between person. ${ }^{*} p<.05 .{ }^{* * *} p<.01$.

Within-person variation in number of stressors and stressor severity was unrelated to daily PA reports, and GPS did not moderate any of the aforementioned within-person associations (all ps $>.25)$.

\section{Discussion}

The results of the present study present a number of findings. First, we observed that older adults reported a lower frequency of daily stressor occurrence than younger adults. Second, across stress days, younger adults reported more stressors per day than did older adults; however, stressor severity ratings between the two groups were comparable. Third, younger and older adults reported significantly higher levels of NA on stress days compared with nonstress days, whereas only older adults exhibited stress-related reductions of PA. Fourth, GPS was associated with greater reported daily stressor exposure among older adults, greater numbers of reported stressors across stress days in both age groups, and stress-related increases in NA in both age groups, but this effect was slightly stronger for younger adults. Finally, greater number and severity of stressors reported were associated with higher levels of NA, within persons across stress days, among younger but not older adults.

Consistent with previous research (Almeida \& Horn, 2004; Zautra et al., 1991), we found that older adults report experiencing considerably fewer daily stressors than younger adults. This is consistent with theoretical accounts (e.g., Carstensen et al., 2003, 1999) that predict that old age is characterized by a shift in motivation to avoid situations that potentially result in the experience of negative emotions. Although this result is consistent with such a theoretical account, the age difference in stressor exposure could also be due to physical and health limitations experienced by the very old adults included in the older adult sample. These individuals may have had reduced stressor exposure because of health frailties that potentially constrain the types of activities they can engage in and, subsequently, opportunities for experiencing stressors. Unfortunately, the present data cannot be used to examine either the motivational explanation or physical limitation explanation for the age differences in daily stressor exposure, but this could be an interesting topic for future research.

We also extended this previous work to show that across days when daily stressors are reported, younger adults report, on average, greater numbers of stressors per day, but the two groups reported the stressors they experience to be of comparable severity. The age difference in number of stressors reported across stress days, however, was reduced to a nonsignificant level once we considered the effect of GPS. This pattern of results suggests that the characteristics of the stress day, or how people interpret and report the events of their daily lives, may be somewhat different for younger and older adults, but these differences appear to be influenced by how stressful individuals report their lives to be currently.

Table 6

Multilevel Model Parameter Estimates of the Within-Person Association Between the Number of Stressors, Severity of Stressors, and Daily Affect Reports Across Stress Days

\begin{tabular}{|c|c|c|c|c|c|c|c|c|}
\hline \multirow[b]{3}{*}{ Variable } & \multicolumn{4}{|c|}{ Negative affect } & \multicolumn{4}{|c|}{ Positive affect } \\
\hline & \multicolumn{2}{|c|}{ Number of stressors } & \multicolumn{2}{|c|}{ Severity of stressors } & \multicolumn{2}{|c|}{ Number of stressors } & \multicolumn{2}{|c|}{ Severity of stressors } \\
\hline & Estimate & $S E$ & Estimate & $S E$ & Estimate & $S E$ & Estimate & $S E$ \\
\hline \multicolumn{9}{|c|}{ Within-person effect } \\
\hline Younger & .43 & $.19^{*}$ & .23 & $.11^{*}$ & .06 & .26 & -.09 & .15 \\
\hline Older & .04 & .20 & -.05 & .10 & .13 & .24 & .16 & .12 \\
\hline Difference & .40 & .27 & .28 & $.15^{\dagger}$ & -.07 & .35 & -.25 & .19 \\
\hline
\end{tabular}

${ }^{\dagger} p<.10 . \quad{ }^{*} p<.05$. 
We also showed that GPS was reliably associated with greater frequency exposure to daily stressors, but only for older adults. GPS was also associated with greater numbers of stressors across stress days for both younger and older adults, but it was unrelated to the severity ratings of the stressors experienced. This pattern of results suggest that global perceptions of stress are related to the experiencing of daily stressors but not how these stressors are appraised, at least in terms of their subjective severity. These findings are consistent with previous research (van Eck et al., 1998) only observing, however, that this association among older adults was novel. One explanation for this finding is that older adults who perceive themselves as overburdened are more likely to perceive events in their daily lives as stressors because of agerelated reductions in the cognitive, physical, and social resources necessary for coping with additional stressors. Younger adults, in contrast, possess the necessary resources to accommodate daily stressors despite how overburdened they are currently feeling. Together, these results indicate that age and GPS are both important predictors of daily stressor exposure, with the former being a protective factor and the later a vulnerability factor, particularly in old age.

Consistent with previous research, we observed significant increases in younger and older adults' NA in response to daily stressors; however, there was no age difference in this reactivity, indicating that older adults were not more emotionally reactive to daily stressors than young adults. Furthermore, controlling for daily stress attenuated the age difference in NA. This later finding suggests that experiential factors might drive age differences in daily NA, and not motivational factors as posited by SST (Carstensen, 1995; Carstensen et al., 1999).

GPS moderated the effects of daily stressors on NA, such that individuals reporting higher levels of GPS exhibited greater increases in NA on stressor days. This effect was significant for young adults, but only moderately significant for older adults, indicating that older adults, regardless of level of GPS, exhibited stress-related increases in NA, whereas younger adults high in GPS exhibited greater stress-related increases in NA than their low-GPS counterparts. Thus, for older adults, there is modest evidence that GPS compounds the effects of daily stressors on NA, but there is much stronger evidence for such exacerbation among younger adults.

Although previous research has indicated that reactivity to daily stressors is greater in old age (Mroczek \& Almeida, 2004), the results of the present study did not replicate this finding. There was evidence of a moderately significant age difference in stressrelated changes in NA, but only when the effects of GPS were considered. One possible explanation for this discrepancy is how daily stress was defined in the two studies. In our study, we used a dichotomous variable to define days as stress days versus nonstress days, whereas Mroczek and Almeida (2004) used a severityweighted measure of daily stress. Thus, it is unclear whether the associations observed by Mroczek and Almeida reflect reactivity to the experience of stress or the subjective appraisal of how severe the event was. Another possible explanation for the discrepancy is the ages of the samples used in the studies. The maximum age in Mroczek and Almeida's sample was 74, whereas the average age of an older adult in the present sample was 80 (with a maximum age of 95). Our sample likely represents positively selected samples of older adults, possibly individuals who have mastered how to cope with stress and, therefore, are savvy at tempering their emotional reactions. Less able older adults may be more reactive and could be too ill to participate, possibly because of their stress (e.g., Kiecolt-Glaser \& Glaser, 2001). Furthermore, Mroczek and Almeida's participants were assessed over the phone, whereas the participants in our study had to come to the lab to be assessed. Therefore, physical and health limitations likely stratified our sample. Yet another explanation is that the capacity to integrate and process negative emotions peaks during middle age and then declines, partially because negative emotions are more difficult to process cognitively (Labouvie-Vief, 2003). In Mroczek and Almeida's (2004) sample, which spanned midlife (25-74 years old), individuals may have been at their peak capacity for processing and integrating negative emotions, whereas the older adults in the present study may not have had the cognitive resources necessary to fully process and experience their negative emotions. Thus, age-related declines in cognitive abilities may help to buffer against the intensity of negative emotional experiences. Future research could examine the extent to which health and cognitive function predict daily stressor-related changes in NA, and whether age moderates any such associations.

For PA, we observed daily stressor-related decreases in PA, but only for older adults. Younger adults exhibited a nonsignificant decrease, and the difference in the daily stressor effect between younger and older adults was not statistically significant. Although the negative effect of daily stressors on PA in older adults stands in contrast to Uchino et al. (2006), the lack of an age effect on stress-related changes in PA is consistent with Uchino and colleagues. Nonetheless, very old adults did exhibit decreases in PA in response to daily stressors, providing one of the first demonstrations of such an effect. We also examined whether GPS moderated the effect of daily stressors on PA and found no evidence to support such a claim. Taken together, this result suggests that daily stressors decrease PA, but only for very old adults.

Previous results from ecological momentary assessment studies have shown decreases and increases in PA associated with the experience of stress (Smyth et al., 1998; Uchino et al., 2006; van Eck et al., 1998). The samples obtained in these studies comprised middle-aged adults ( 37 years, 42 years, and 53 years for Smyth et al. (1998), Uchino et al. (2006), and van Eck et al. (1998), respectively), whereas we had samples of both younger $\left(M_{\text {age }}=\right.$ $20)$ and older $\left(M_{\text {age }}=80\right)$ adults and only observed an effect for the latter. Thus, the existing evidence seems to suggest that the effects of daily stressors on PA depend on one's age, and the relationship may be nonlinear. Sociodemographic factors may also be important moderators of the effect of GPS on stress-related decreases in PA. van Eck et al. (1998) found that GPS exacerbated stress-related changes in PA; however, we did not. Our sample comprised primarily women, whereas van Eck's sample comprised entirely men. If the association between GPS and daily stressors on PA is stronger in men, then the small percentages of men included in the present study may account for the differences in findings.

The present study also extends previous research examining emotional reactions to daily stressful events by considering intraindividual variability in the characteristics of what constitutes a stress day. Results revealed significant within-person variation in the number of stressors and severity of stressors reported across stress days. For younger adults, not only does NA increase on stress days compared with nonstress days, but this effect is com- 
pounded on stress days when more stressors are reported than usual as well as when the stressors reported are more severe than usual. Variation in number and severity of stressors was not significantly related to NA among older adults, nor was this variation related to PA for either age group. Furthermore, GPS did not moderate any of the intraindividual associations among stress day characteristics and emotional reactions. Together, these results indicate that for older adults, emotional reactions to daily stress are primarily driven by whether an event occurred on a given day, whereas the number and severity of the stressors reported compound younger adults' emotional reactivity.

\section{Limitations}

One limitation of the present study is its cross-sectional design. Although the results of the present study can speak to age differences in exposure and reactivity to daily stressors, they cannot inform how exposure and reactivity to daily stressors change with increasing age. Also, the cross-sectional design cannot definitely show whether exposure and emotional reactivity to daily stressors influence GPS, whether GPS influences exposure and emotional reactivity to daily stressors, or whether these variables have dynamic reciprocal relationships. Furthermore, it is unclear whether the measure of GPS reflects a stable individual-differences characteristic (high-stress person vs. low-stress person) or information about the context when the person was assessed (high-stress time vs. low-stress time), or both. Individuals would need to be assessed longitudinally in order to address these issues. Another limitation is the small sample size, particularly the number of younger adults. The power to detect between-person associations (e.g., GPS and exposure to daily stressors) is quite low, especially in the sample of younger adults. The small sample size also precluded examination of differences in the frequency and reactivity on the basis of the types of stressors reported. A final limitation involves our assessment of individuals in a laboratory environment, as opposed to adopting a more ecologically valid method for collecting data. As such, more ecologically valid assessments of stress and affect in future aging research are needed to compliment findings obtained in the laboratory.

\section{Conclusions}

The results of the present study indicate that both age and GPS act as important factors associated with exposure and emotional reactivity to daily stressors. In addition, the present results show that not all stress days are the same, and it is important to consider intraindividual variability in the characteristics of the stress day, including number of stressors and severity of stressors, when examining emotional reactivity to daily stress. For older adults, emotional reactions to daily stressors are driven by the mere occurrence of an event, whereas with younger adults, characteristics of the stress day compound their emotional reactions. Together, these results suggest that when examining exposure and reactivity to daily stressors, there are age differences in the characteristics of a stress day as well as age differences in what catalyzes emotional reactions to daily stressors.

\section{References}

Almeida, D. M. (2005). Resilience and vulnerability to daily stressors assessed via dairy methods. Current Directions in Psychological Science, 14, 64-68.

Almeida, D. M., \& Horn, M. C. (2004). Is daily life more stressful during middle adulthood? In O. G. Brim, C. D. Ryff, \& R. C. Kessler (Eds.), How healthy are we? A national study of well-being at midlife (pp. 425-451). Chicago: The University of Chicago Press.

Almeida, D. M., \& Kessler, R. C. (1998). Everyday stressors and gender differences in daily distress. Journal of Personality and Social Psychology, 75, 670-680.

Almeida, D. M., Wethington, E., \& Kessler, R. C. (2002). The Daily Inventory of Stressful Experiences (DISE): An interview-based approach for measuring daily stressors. Assessment, 9, 41-55.

Baum, A., \& Posluszny, D. M. (1999). Health psychology: Mapping biobehavioral health contributions to health and illness. Annual Review of Psychology, 50, 137-163.

Bolger, N., DeLongis, A., Kessler, R. C., \& Schilling, E. A. (1989). Effects of daily stress on negative mood. Journal of Personality and Social Psychology, 57, 808-818.

Bolger, N., \& Schilling, E. A. (1991). Personality and problems of everyday life: The role of neuroticism in exposure and reactivity to daily stressors. Journal of Personality, 59, 356-386.

Bolger, N., \& Zuckerman, A. (1995). A framework for studying personality in the stress process. Journal of Personality and Social Psychology, 69, 890-902.

Carstensen, L. L. (1995). Evidence for a life-span theory of socioemotional selectivity. Current Directions in Psychological Science, 4, 151-156.

Carstensen, L. L., Fung, H., \& Charles, S. (2003). Socioemotional selectivity theory and the regulation of emotion in the second half of life Motivation and Emotion, 27(2), 103-123.

Carstensen, L. L., Isaacowitz, D. M., \& Charles, S. (1999). Taking time seriously: A theory of socioemotional selectivity. American Psychologist, 54, 165-181.

Cohen, S., Kamarck, T., \& Marmelstein, R. (1983). A global measure of perceived stress. Journal of Health and Social Behavior, 24, 385-396.

Fredrickson, B. L. (2001). The role of positive emotions in positive psychology: The broaden-and-build theory of positive emotions. American Psychologist, 56, 218-226.

Fredrickson, B. L., \& Joiner, T. (2002). Positive emotions trigger upward spirals toward emotional well-being. Psychological Science, 13, 172175.

Grzywacz, J. G., Almeida, D. M., Neupert, S. D., \& Ettner, S. L. (2004). Socioeconomic status and health: A microlevel analysis of exposure and vulnerability to daily stressors. Journal of Health and Social Behavior, $45,1-16$.

Kiecolt-Glaser, J. K., \& Glaser, R. (2001). Stress and immunity: Age enhances the risks. Current Directions in Psychological Science, 10, $18-21$.

Kiecolt-Glaser, J. K., McGuire, L., Robles, T. F., \& Glaser, R. (2002) Psychoneuroimmunology: Psychological influences on immune function and health. Journal of Consulting and Clinical Psychology, 70, 537-547.

Labouvie-Vief, G. (2003). Dynamic integration: Affect, cognition, and the self in adulthood. Current Directions in Psychological Science, 12, 201-206.

Lawton, M. P., Kleban, M., Dean, J., Rajagopal, D., \& Parmelee, P. (1992). The factorial generality of brief positive and negative affect measures. Journal of Gerontology: Psychological Sciences, 47, 228-237.

Lazarus, R. S. (1999). Stress and emotion: A new synthesis. New York: Springer.

Marco, C. A., \& Suls, J. (1993). Daily stress and the trajectory of mood: Spillover, response assimilation, contrast, and chronic negative affectivity. Journal of Personality and Social Psychology, 64, 1053-1063.

Mroczek, D. K., \& Almeida, D. M. (2004). The effect of daily stress, 
personality, and age on daily negative affect. Journal of Personality, 72, 355-378.

Pinquart, M., \& Sörenson, S. (2003). Differences between caregivers and noncaregivers in psychological health and physical illness: A metaanalysis. Psychology and Aging, 18, 250-267.

Serido, J., Almeida, D. M., \& Wethington, E. (2004). Chronic stressors and daily hassles: Unique and interactive relationships with psychological distress. Journal of Health and Social Behavior, 45, 17-33.

Sliwinski, M. J., Smyth, J. M., Hofer, S. M., \& Stawski, R. S. (2006). Intraindividual coupling of daily stress and cognition. Psychology and Aging, 21, 545-557.

Smyth, J., Ockenfels, M., Porter, L., Kirschbaum, C., Hellhammer, D., \& Stone, A. (1998). The association between daily stressors, mood and salivary cortisol secretion. Psychoneuroendocrinology, 23, 353370.

Snidjers, T. A. B., \& Bosker, R. J. (1999). Multilevel analysis: An introduction to basic and advanced multilevel modeling. London: Sage.

Uchino, B. N., Berg, C. A., Smith, T. W., Pearce, G., \& Skinner, M. (2006). Age-related differences in ambulatory blood pressure reactivity during stress: Evidence for greater blood pressure reactivity with age. Psychology and Aging, 21, 231-239.

van Eck, M., Nicolson, N. A., \& Berkhof, J. (1998). Effects of stressful daily events on mood states: Relationship to global perceived stress. Journal of Personality and Social Psychology, 75, 1572-1585.

Watson, D. (1988). Intraindividual and interindividual analyses of positive and negative affect: Their relation to health complaints, perceived stress, and daily activities. Journal of Personality and Social Psychology, 54, $1020-1030$

Watson, D., Clark, L. A., \& Tellegen, A. (1988). Development and validation of brief measures of positive and negative affect: The PANAS scales. Journal of Personality and Social Psychology, 54, 1063-1070.

Zautra, A. J. (2003). Emotions, stress, and health. New York: Oxford University Press.

Zautra, A. J., Affleck, G. G., Tennen, H., Reich, J. W., \& Davis, M. C. (2005). Dynamic approaches to emotions and stress in everyday life: Bolger and Zuckerman reloaded with positive as well as negative affects. Journal of Personality, 73, 1511-1538.

Zautra, A. J., Finch, J. F., Reich, J. W., \& Guarnaccia, C. A. (1991). Predicting the everyday life events of older adults. Journal of Personality, 59, 507-538.

Received February 19, 2007

Revision received September 7, 2007

Accepted September 18, 2007

\section{Members of Underrepresented Groups: Reviewers for Journal Manuscripts Wanted}

If you are interested in reviewing manuscripts for APA journals, the APA Publications and Communications Board would like to invite your participation. Manuscript reviewers are vital to the publications process. As a reviewer, you would gain valuable experience in publishing. The P\&C Board is particularly interested in encouraging members of underrepresented groups to participate more in this process.

If you are interested in reviewing manuscripts, please write to the address below. Please note the following important points:

- To be selected as a reviewer, you must have published articles in peer-reviewed journals. The experience of publishing provides a reviewer with the basis for preparing a thorough, objective review.

- To be selected, it is critical to be a regular reader of the five to six empirical journals that are most central to the area or journal for which you would like to review. Current knowledge of recently published research provides a reviewer with the knowledge base to evaluate a new submission within the context of existing research.

- To select the appropriate reviewers for each manuscript, the editor needs detailed information. Please include with your letter your vita. In the letter, please identify which APA journal(s) you are interested in, and describe your area of expertise. Be as specific as possible. For example, "social psychology" is not sufficient-you would need to specify "social cognition" or "attitude change" as well.

- Reviewing a manuscript takes time (1-4 hours per manuscript reviewed). If you are selected to review a manuscript, be prepared to invest the necessary time to evaluate the manuscript thoroughly.

Write to Journals Office, American Psychological Association, 750 First Street, NE, Washington, DC 20002-4242. 